
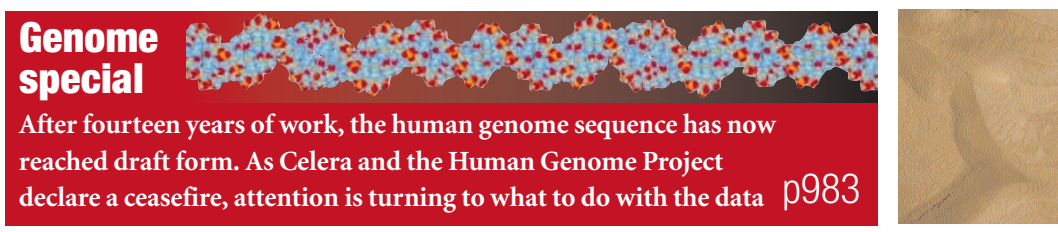

Red liquid
Possible water
courses on Mars
galvanize NASA
p987

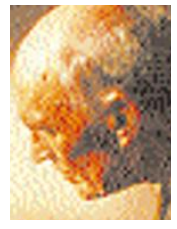

Patent saved

Alzheimer's

research using mice protected in court p989

\title{
World leaders heap praise on human genome landmark
}

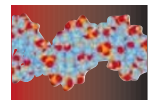

Colin Macilwain, Washington

It was portrayed as the scientific rivalry to end all scientific rivalries. But after two years of often acrimonious competition, the principal players in the Human Genome Project (HGP) came together on Monday this week with Craig Venter, president of Celera Genomics of Rockville, Maryland, to praise one another's achievements - and to bask in the adulation of their political leaders.

Those achievements - the compilation of a 'working draft' of the human genome by the HGP and Celera's 'first assembly' of a complete genome sequence - may in reality represent arbitrary milestones on the way to the goal of fully deciphering the human genetic code. But for those scientists who have devoted their careers to genomics since the launch of the HGP more than a decade ago, a public celebration is welcome.

In Washington, President Bill Clinton hosted an event at the White House with Venter and Francis Collins, director of the National Human Genome Research Institute in Bethesda, Maryland - joined by video link from London by Prime Minister Tony Blair. In Paris, Tokyo and Bonn, other members of the international HGP consortium made their own announcements. The Wellcome Trust, the main backer of the Sanger Centre near Cambridge, responsible for one third of the HGP sequence, hosted its own press conference in London.

Turning to James Watson, discoverer with Francis Crick of the structure of DNA and head of the HGP until 1992, Clinton described the 1953 Nature paper, which noted the structure's "novel features, which are of considerable biological interest" as "one of the great understatements of all time". This time, understatement was in short supply. "With this profound new knowledge, humankind is on the verge of gaining immense, new power," said Clinton.

Mike Dexter, director of the Wellcome Trust, went so far as to describe the project's significance as surpassing the invention of the wheel. "I can see technology making the wheel obsolete," he said. "But this code will be useful and used as long as humans exist."

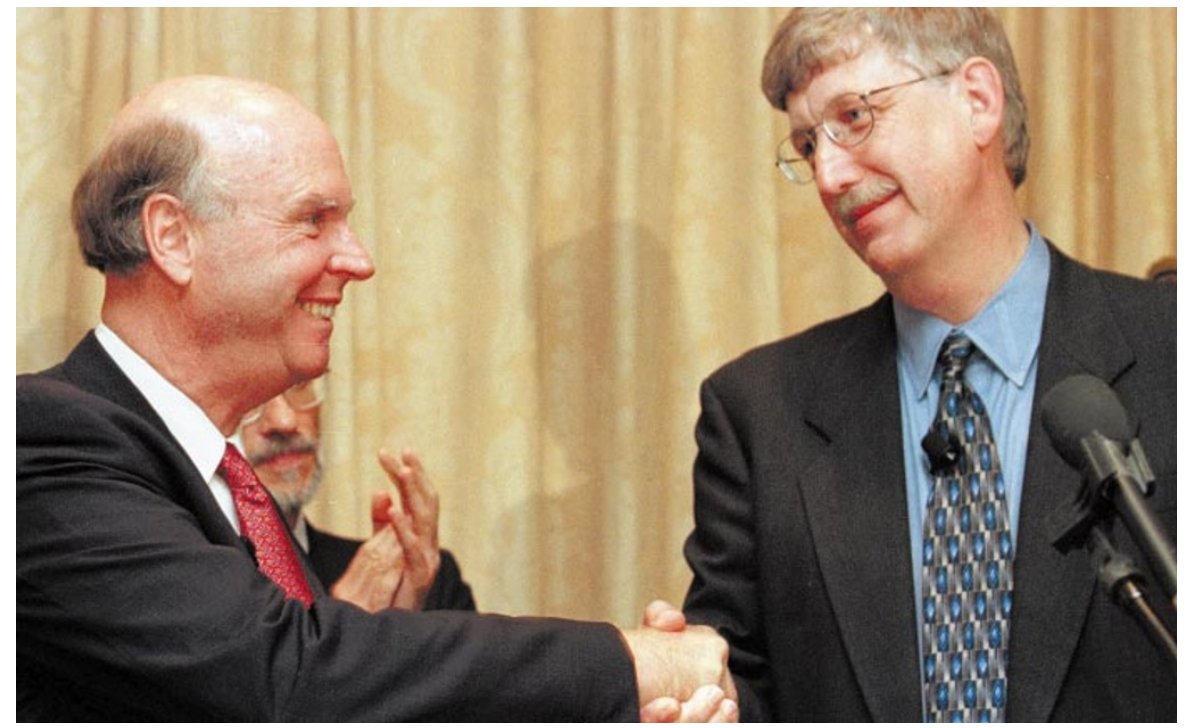

Truce: Venter (left) and Collins bury their differences for the joint announcement of the draft map.

For some scientists, this may seem like hyperbole - particularly as the value of both the HGP and Celera drafts, in their current form, remains unclear. The sequences are difficult to compare, because of the two groups' different approaches. Celera's 'whole-genome shotgun' strategy relied on shattering the entire genome into tiny pieces, sequencing these en masse, and then using sophisticated computer algorithms to put the pieces back together. The HGP cloned larger overlapping fragments of the genome into some 24,000 bacterial artificial chromosomes, and sequenced these one by one.

The HGP claims to have cloned $97 \%$ of the genome, and sequenced $85 \%$ of it to draft standard. That falls short of the $90 \%$ figure set as a target for the working draft — although this should be achieved within a few weeks. On average, the HGP has sequenced each base seven times over (7X coverage). Celera's assembly gives $4.6 \mathrm{X}$ coverage — some way

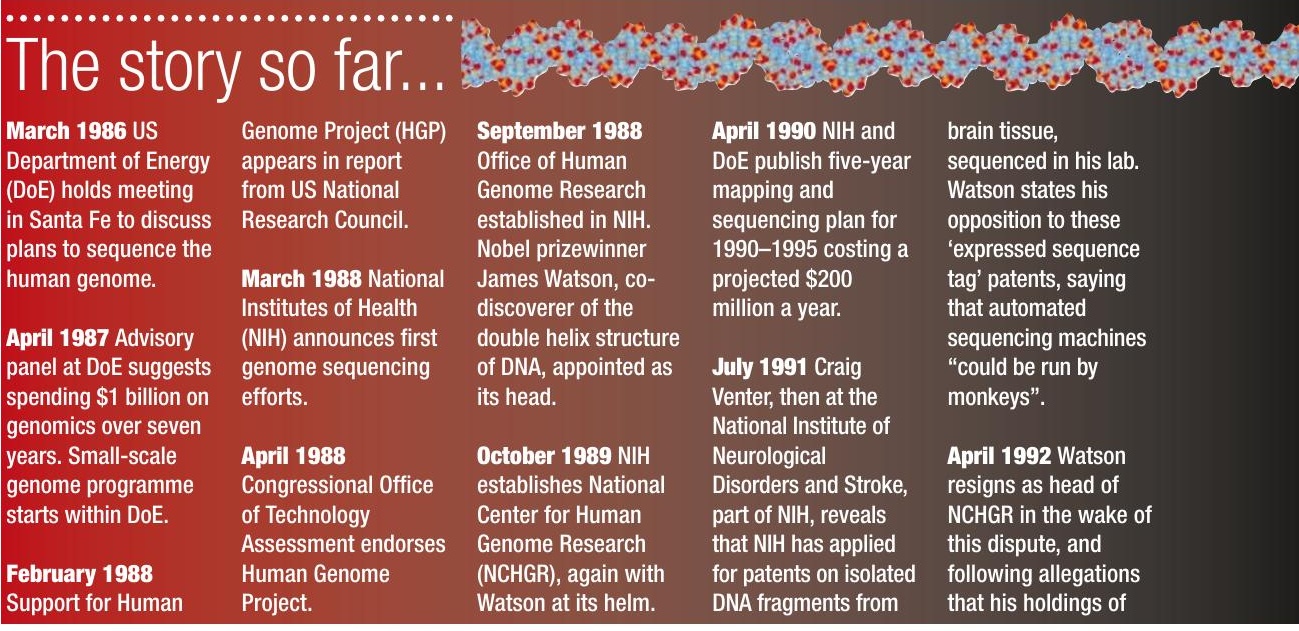


from the 10X it originally promised in 1998, although the company says its sequence covers $99 \%$ of the genome. On the basis of the data presented publicly, it is impossible to verify whether Celera's assembly is correctly orientated and ordered throughout the genome. But Celera has also produced a second map by incorporating data from the public project which will increase its depth of coverage and allow it to check its shotgun assembly.

Despite the preliminary nature of both sets of data, the White House has been encouraging the two projects to bury their differences and declare their drafts complete. US politicians were appalled at the media portrayal of the sequencing project as a battle between Celera and the HGP. Clinton's aides hope that a joint announcement will end the rancour and lead to greater public recognition of the achievements of both projects.

The rapprochement between Collins and Venter was brokered by senior figures including Eric Lander, director of the Whitehead Institute at the Massachusetts Institute of Technology, one of the main sequencing centres for the HGP, and Ari Patrinos, head of biological and environmental research at the Department of Energy, who hosted meetings over beer and pizza at his home in Rockville. The agreement has four parts: Monday's choreographed joint announcement; a pledge

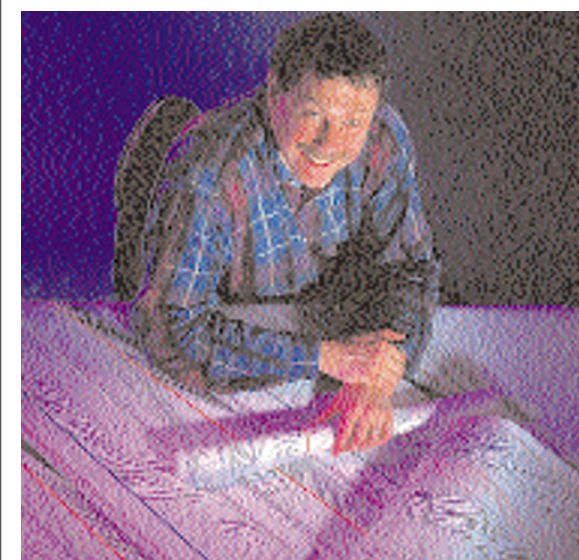

Lander: helped to broker a genomic ceasefire. to publish the two draft sequences, simultaneously but separately, later in the year; a loosely defined plan to hold a joint meeting of the two research teams after publication; and a promise to keep open lines of communication between the HGP and Celera.

At the White House event, Collins struck a spiritual note: "It is humbling for me and aweinspiring to realize that we have caught the first glimpse of our own instruction book, previously known only to God." Venter was philosophical: "The complexities and wonder of how the inanimate chemicals that are our genetic code give rise to the imponderables of the human spirit should keep poets and philosophers inspired for the millenniums."

For scientists working on the HGP, the main hope is that the task of finishing the genome sequence does not get subordinated to other activities. Parallels drawn with the Apollo lunar programme - which soon fizzled out after the space race was won - provide a warning. "What we most want to avoid is the fate of achieving this heroic goal at such great cost and to the neglect of the long-term goals," says Maynard Olson, a geneticist at the University of Washington in Seattle. Additional reporting from David Dickson in London.

\section{Draft data leave geneticists with a mountain still to climb}

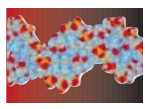

Declan Butler and Paul Smaglik Now the race to obtain a draft sequence of the human genome has been declared an honourable draw, attention will switch to the task of finishing the sequence and 'annotating' the entire genome - characterizing all its genes and working out their functions. The annotation is so formidable that it may need the largest Internet 'collaboratory' yet attempted.

Given that Celera has now stopped sequencing, the task of finishing the genome - in which, to ensure accuracy, each base has been sequenced 10 times over (10X coverage) - will fall to the public Human Genome Project (HGP). In that regard, says Tim Hubbard of the Sanger Centre at Hinxton, near Cambridge, the HGP got a pleasant surprise last weekend, when its data were subjected to a "brute force" computer analysis. Hubbard had expected to find that the HGP had sequenced the genome to an average depth of 5X, but instead, a figure of 7X emerged. This, and the fact that the draft seems to contain fewer gaps than expected, bodes well for finishing the genome ahead of the stated 2003 deadline, says Hubbard.

But annotation poses a much bigger challenge. The first step is to identify all of the protein-coding regions, which will give a good idea of how many genes there are. Most geneticists think the figure lies somewhere between 35,000 and 150,000 . Beyond that will come detailed studies of the structure of individual genes, including their regulatory elements, and attempts to assign functions to them.

David Lipman, director of the National Center for Biotechnology Information (NCBI) in Bethesda, Maryland, believes that the draft sequence will allow researchers to use computational tools to pinpoint the position of many of the gene fragments catalogued in cDNA libraries of expressed genes. In many cases, it will then be possible to extract an entire gene from the draft sequence - and by comparison with other genes, begin to establish its function. But many biologists are unconvinced. "The current perception is that annotating finished sequence is much less difficult than annotating 'sequence in progress,'” says Richard Gibbs of Baylor College of Medicine in Houston. "And no matter how

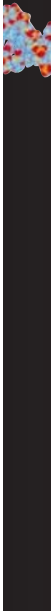

cem

\section{Medicine in Houston. "And no matter how}




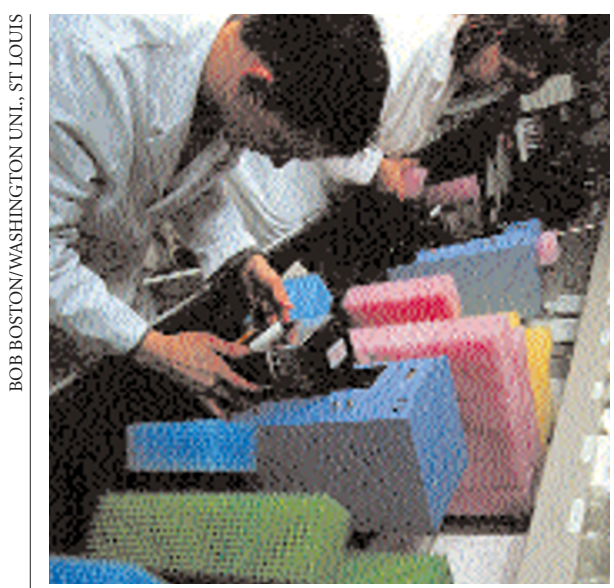

Carry on sequencing: genome scientists, here preparing DNA for analysis, will get no respite.

you cut it, the draft is sequence in progress."

Even with the finished sequence in hand, experience with the two human chromosomes for which this has been achieved numbers 21 and 22 - indicates that annotating the genome will be a mammoth task. "With 21 and 22 it was not possible to reliably identify and delineate all of the genes," says Philip Green, a biocomputing expert at the University of Washington in Seattle.

In the case of the genome of the fruitfly Drosophila, annotation was kickstarted by a two-week 'jamboree' held at Celera. This brought together over 40 academic fly geneticists and 50 Celera scientists, and compared the outcome of dozens of different annotation techniques. This experience should serve Celera well. "We basically trained their annotation team to annotate the human genome," observes Martin Reese, formerly of the Drosophila Genome Center at the Lawrence Berkeley National Laboratory in California and now with ValiGen, a company near Paris.

The news that Celera and HGP researchers will hold a joint scientific meeting after publishing simultaneous papers of their

Work in progress: data have accumulated rapidly but the public sequence is far from finished. draft sequences (see lead story) initially raised hopes of a similar human jamboree. However, as HGP head Francis Collins pointed out to Nature, Celera cannot really share its annotation, as it will be its core product for sale to its subscribers. Rather, the meeting is expected to look at discrepancies between the public and private sequences with the goal of 'cleaning up' one another's data.

Celera has said little publicly about its annotation capacity, but it uses specialized software to combine the output of multiple gene finding tools - mostly those available to the public sector. But while Celera's annotation team is at the cutting edge, many experts argue that no single team is currently in a position to annotate the entire genome. "No one really knows how to do it completely," says John Quackenbush of The Institute for Genomic Research in Rockville, Maryland.

On the public side, annotating the genome might mean a rethink on how the HGP's data are organized. Lipman acknowledges that the main sequence database, NCBI's Genbank, has its limitations. "It does not represent what we know of biology at any given time," he says. "It only represents what the author put in." Indeed, while scientists deposit data in Genbank because many journals make this a condition for publication, some do not bother to correct and update it.

"With annotation we will need much more active curation," says Lipman. Many experts believe this may require a 'collabora- tory' approach, using the Internet to leverage the talent of biologists worldwide. The NCBI intends to set up a system in which named biologists around the world will 'adopt' a gene or gene family, becoming the curators responsible for gathering information from the wider research community. But Lipman remains against the idea of a free-for-all in which any biologist can annotate the genome - the problem, he says, is that most do not fully understand database syntax, and so tend to make errors when they input data. "What we really want is their knowledge," says Lipman.

The Ensembl annotation project, run by the Sanger Centre and the European Bioinformatics Institute, is plotting a genuinely distributed effort. Hubbard foresees a system where a geneticist in Germany could annotate a gene online, and have his or her interpretation challenged almost in real time by a biologist in Boston. Ensembl's vision has been inspired by a radical suggestion, made by Tom Slezak of the Lawrence Livermore National Laboratory in California and Lincoln Stein of the Cold Spring Harbor Laboratory on Long Island, to use 'Napster' technology for genome annotation. This allows computer users worldwide to share MP3 music files, and could, in theory, let biologists share and annotate genome data (see Nature 404, 694; 2000). If these ideas catch on, the genome project's future could be one of annotation by anarchy.

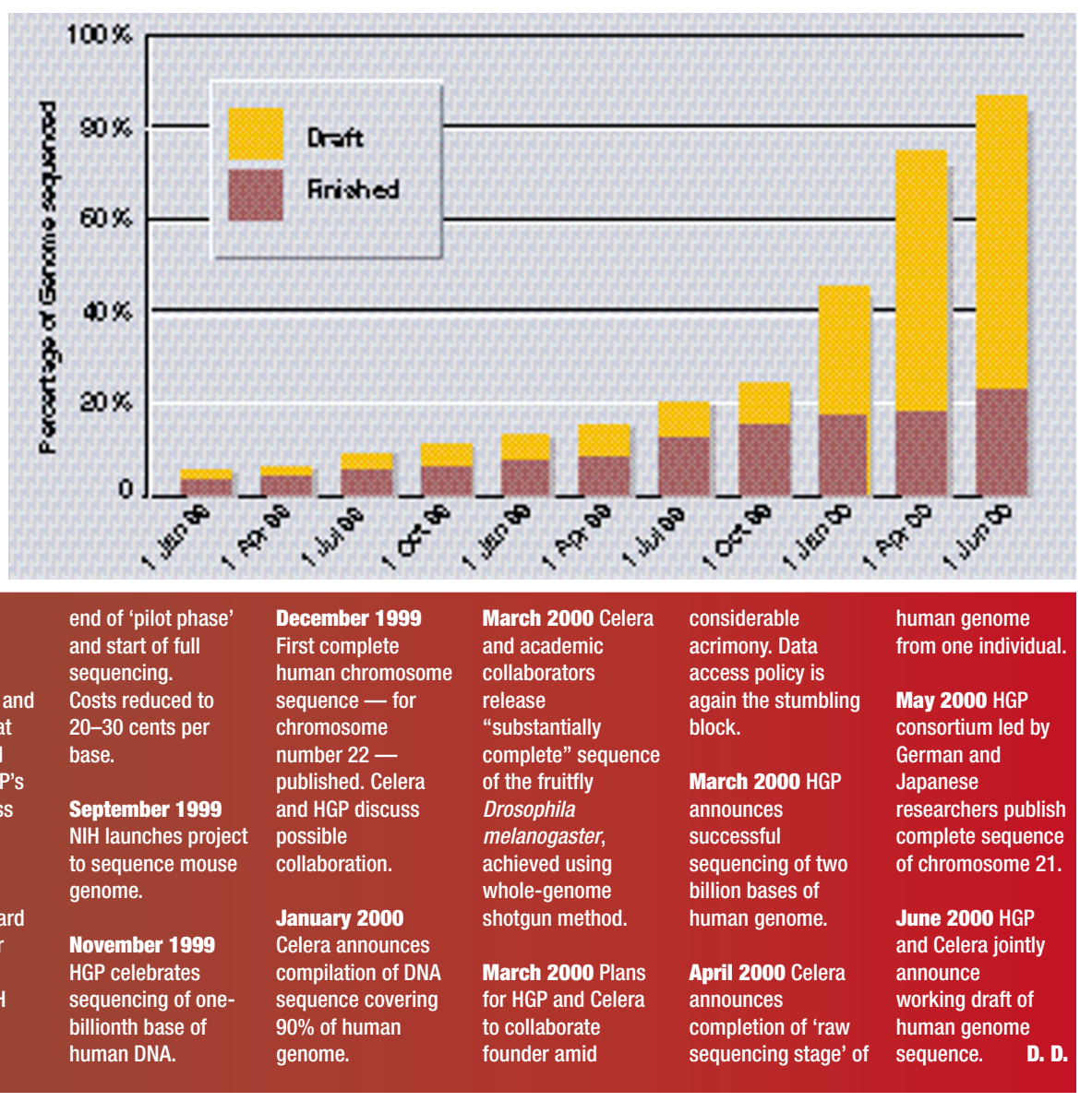

